\title{
Noncatalytic Oxidative Coupling of Methane (OCM): Gas-Phase Reactions in a Jet Stirred Reactor (JSR)
}

\author{
Haoyi Wang, Can Shao, Jorge Gascon, Kazuhiro Takanabe, and S. Mani Sarathy* \\ Cite This: https://doi.org/10.1021/acsomega.1c05020 \\ Read Online
}

ACCESS

Wlll Metrics \& More

Article Recommendations

Supporting Information

ABSTRACT: Oxidative coupling of methane (OCM) is a promising technique for converting methane to higher hydrocarbons in a single reactor. Catalytic OCM is known to proceed via both gas-phase and surface chemical reactions. It is essential to first implement an accurate gas-phase model and then to further develop comprehensive homogeneous-heterogeneous OCM reaction networks. In this work, OCM gas-phase kinetics using a jet-stirred reactor are studied in the absence of a catalyst and simulated using a 0-D reactor model. Experiments were conducted in OCM-relevant operating conditions under various temperatures, residence times, and inlet $\mathrm{CH}_{4} / \mathrm{O}_{2}$ ratios. Simulations of different gas-phase models related to methane oxidation were implemented and compared against the experimental data. Quantities of interest (QoI) and rate of production analyses on

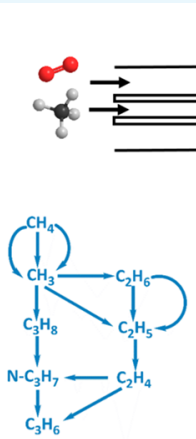

Reaction Pathways

Jet-Stirred Reactor hydrocarbon products were also performed to evaluate the models.

The gas-phase models taken from catalytic reaction networks could not adequately describe the experimental gas-phase performances. NUIGMech1.1 was selected as the most comprehensive model to describe the OCM gas-phase kinetics; it is recommended for further use as the gas-phase model for constructing homogeneous-heterogeneous reaction networks.

\section{INTRODUCTION}

Due to increasingly strict regulations on carbon emissions, production of natural gas (mainly $\mathrm{CH}_{4}$ ) has increased dramatically over the past decade and is expected to continue to expand in the foreseeable future. Because of its relatively low economic value, natural gas is attracting worldwide attention by utilizing $\mathrm{CH}_{4}$ in more valuable chemicals, rather than as an energy source. The oxidative coupling of methane (OCM) is considered to be one of the important routes for directly converting methane into more desirable and valuable higher hydrocarbons, such as olefins, in the presence of catalysts. This process was first introduced by Keller and Bhasin in the $1980 \mathrm{~s}^{1}$ and it has been exhaustively studied over the years to explore suitable catalysts and to find fundamental kinetic studies for commercialization. Other than traditional thermocatalysis, the OCM process has also been developed at ambient temperatures with the application of visible light and electric fields. ${ }^{2,3}$ Recently, Siluria Technologies developed several patented technologies and constructed pilot plant units, upgrading the scale for OCM commercialization. ${ }^{4,5}$ The OCM process has not yet been fully commercialized and still requires better understanding of both reaction kinetics and catalytic performances on a targeted single pass yield for $\mathrm{C}_{2}$ products. ${ }^{6}$

The generally accepted OCM pathways consist of both gasphase (homogeneous) and surface-catalyzed (heterogeneous) reaction networks. $^{6-11}$ Oxygen is first adsorbed and dissociated into surface-active oxygen species $\left(\mathrm{O}^{*}\right)$ in the presence of a catalyst surface (eq 1). One methyl radical then forms via the hydrogen abstraction between $\mathrm{CH}_{4}$ and $\mathrm{O}^{*}$, whereas two methyl radicals combine in the gas phase to form ethane (eqs 2 and 3). The secondary reaction product ethylene is then formed via dehydrogenation of ethane in both the gas-phase and surface reactions.

$$
\begin{aligned}
& \mathrm{O}_{2}+2 * \leftrightarrow 2 \mathrm{O}^{*} \\
& \mathrm{CH}_{4}+\mathrm{O}^{*} \rightarrow \mathrm{CH}_{3} \cdot+\mathrm{OH}^{*} \\
& 2 \mathrm{CH}_{3} \cdot \rightarrow \mathrm{C}_{2} \mathrm{H}_{6}
\end{aligned}
$$

The effect of adding water vapor over OCM has been reported to depend on the composition of the catalyst. ${ }^{10}$ For example, $\mathrm{Mn} / \mathrm{Na}_{2} \mathrm{WO}_{4} / \mathrm{SiO}_{2}$ shows the promotional effect of water vapor at high reaction temperatures above $800{ }^{\circ} \mathrm{C},{ }^{8,12}$ whereas water vapor deactivates $\mathrm{Li} / \mathrm{MgO}$ by gradually removing lithium. ${ }^{13}$ From the analysis of reaction pathways of $\mathrm{Mn} / \mathrm{Na}_{2} \mathrm{WO}_{4} / \mathrm{SiO}_{2}$, the $\mathrm{OH}$-mediated reaction pathways are favored for higher yields than surface-mediated path-

Received: September 10, 2021

Accepted: November 15, 2021 
Table 1. General Information of Selected Gas-Phase Models

\begin{tabular}{|c|c|c|c|c|c|}
\hline name & year & ref & \# of species & \# of reactions & notes \\
\hline 1. AramcoMech3.0 & 2018 & 59 & 579 & 3037 & developed based on AramcoMech $1.3 \& 2.0^{60,66}$ \\
\hline 2. $\mathrm{CRECK}\left(\mathrm{C}_{0}-\mathrm{C}_{3}\right)$ & 2020 & 61 & 114 & 1941 & developed upon AramcoMech2.0 $0^{60}$ and further modified with experimental data \\
\hline 3. GRI-Mech 3.0 & 1999 & 62 & 53 & 325 & successor of GRI-Mech 2.11 \\
\hline 4. Karakaya model & 2018 & 31 & 23 & 39 & adapted from Sun et $a l^{26}$ and modified based on experimental data \\
\hline 5. NUIGMech1.1 & 2020 & 63 & 2746 & 11,270 & developed based on experimental and theoretical studies ${ }^{70-73}$ \\
\hline 6. Quiceno model & 2003 & 64 & 29 & 78 & adapted and reduced from the Karbach model ${ }^{69}$ for CPO \\
\hline 7. Schwarz model & 2014 & 55 & 49 & 328 & reduced model of Dooley et al. ${ }^{68}$ (derived from AramcoMech1.3 ${ }^{66}$ ) \\
\hline 8. Sun model & 2008 & 26 & 23 & 39 & reduced and modified from the experimental study of Chen et al. ${ }^{19}$ \\
\hline 9. USC Mech II & 2007 & 65 & 111 & 784 & developed based GRI-Mech $3.0^{62}$ and other experimental studies ${ }^{74-76}$ \\
\hline
\end{tabular}

ways. ${ }^{8,12}$ Hydroxyl radicals ( $\mathrm{OH} \cdot$ ) are believed to be generated from water vapor and oxygen in the gas phase, with the presence of a catalyst surface, and abstract hydrogen from methane for initiation (eqs 4 and 5). To support this theory, the formation of hydroxyl radicals has been directly observed using LIF spectroscopy ${ }^{14}$ and the contribution of the hydroxyl radical generation rate in the gas-phase network on OCM has also been investigated for simulation study, which could theoretically reach the maximum $\mathrm{C}_{2} \mathrm{H}_{4}$ yield of $32 \%$. ${ }^{15}$

$$
\begin{aligned}
& \mathrm{O}_{2}+2 \mathrm{H}_{2} \mathrm{O} \leftrightarrow 4 \mathrm{OH} \cdot \\
& \mathrm{CH}_{4}+\mathrm{OH} \cdot \rightarrow \mathrm{CH}_{3} \cdot+\mathrm{H}_{2} \mathrm{O}
\end{aligned}
$$

Several homogeneous-heterogeneous OCM mechanisms have been developed based on experimental results with different catalysts to better understand the kinetics of the OCM process and to further screen the maximum achievable $\mathrm{C}_{2}$ yield with optimum operating conditions. In early studies, a homogeneous-heterogeneous OCM model for $\mathrm{Li} / \mathrm{MgO}$ was established by Shi et al. with 156 gas-phase and 4 surface reactions in which the gas-phase mechanism agreed with the results from the partial oxidation (CPO) of methane. ${ }^{16} \mathrm{~A}$ mechanism was also developed by Mims et al. over a $\mathrm{Li} / \mathrm{MgO}$ catalyst with 447 gas-phase and 4 surface reactions by performing detailed isotopic analysis. ${ }^{17}$ On the other hand, the role of the catalysts was reported to be both a producer and quencher for radicals. Couwenberg et al. ${ }^{18}$ implemented a model with 39 gas-phase chain reactions, coupled with 10 catalytic reactions, to describe the $\mathrm{Li} / \mathrm{MgO}$-based catalysts, in which gas-phase chain reactions were adapted and reduced from a homogeneous gas-phase model of OCM by Chen et al. ${ }^{19}$ Based on these 39 gas-phase reactions, several catalytic mechanisms were further developed over different types of catalysts to describe the catalytic behaviors by their properties, connect the performances with catalytic descriptors among different catalysts, and screen for the optimum catalysts. ${ }^{20-31}$ On the other hand, for OCM gas-phase studies, several early studies were investigated by proposing homogeneous models without the presence of a catalyst. ${ }^{19,32-34}$ One of the reduced models, $^{18}$ as previously mentioned, is selected for further comparison. Luo et al. ${ }^{35}$ analyzed the gas-phase reaction network over the $\mathrm{Li} / \mathrm{MgO}$ catalyst with the detection of gasphase intermediate species. Ishioka et al. ${ }^{36}$ also used a machine learning technique to better understand the gas-phase performances against operating conditions from the highthroughput experimental data. In fact, since surface species are difficult to observe or identify, OCM surface kinetics are indirectly investigated experimentally by extrapolating conversion rates and selectivity at zero methane conversion for initiation steps ${ }^{8,12,37-39}$ or by applying isotopic techniques to identify the pathways of products. ${ }^{8,17,40-42}$ Other than these, the parameters of surface elementary reactions (sticking coefficient and activation energy) are estimated mostly via density functional theory (DFT) calculations ${ }^{43-54}$ or Polanyi relationships. $^{20,21,23,25,26}$ It is challenging to precisely predict the entire surface reaction mechanism for OCM, which indicates the critical role of an accurate and reliable gasphase model over the entire mechanism. To fulfill this requirement, gas-phase reaction models should accurately describe well-known homogeneous processes (oxidation, pyrolysis, etc.), either with or without the presence of a catalyst surface. In other words, the heterogeneous mechanism should be developed based on accurate gas-phase reaction models, but not vice versa.

For reactor selection in this study, plug flow reactors (PFRs) are commonly used for experiments on methane oxidation to generate the homogeneous gas-phase model for OCM. ${ }^{10,19,26,32,34,35,55}$ For simulation, they are usually assumed to behave as ideal plug flow reactors (1-D). However, the fluid flow pattern within the reactor (early mixing, radical velocity profiles) can cause variations in the flow regimes, and the transport properties for each species must be well known to accurately define the reaction zone and describe the process. ${ }^{56}$ Also, temperature gradients along the reactor could reach up to several hundred degrees with the exothermic process, complicating the simulation and affecting the model's accuracy in the experimental results. In this study, a jet-stirred reactor (JSR) was selected to study the OCM gas-phase kinetics; it could be assumed to provide homogeneous gas compositions with perfect mixing by carefully selecting the reactor dimensions and operating conditions. ${ }^{57} \mathrm{~A}$ steady state was achieved quickly within the reactor, so it was easy to be modeled as a $0-D$ reactor. ${ }^{58}$ Regarding the exothermicity in methane oxidation, the reactant was highly diluted by inert gas to reduce the existence of the temperature gradient within the reactor in order to describe the process more accurately.

In this work, a gas-phase kinetic study of OCM was performed using a jet-stirred reactor, which could be modeled as a $0-\mathrm{D}$ reactor with ideal mixing. The reactor was tested under various operating conditions, including temperatures, residence times, and inlet $\mathrm{CH}_{4} / \mathrm{O}_{2}$ ratios. Various experimentally validated gas-phase models were also applied under OCM conditions from either strictly gas-phase kinetic studies or from heterogeneous catalysis. Simulations were utilized, given the experimental boundary conditions, and employed to identify the influence of various operating conditions. Quantities of interest (QoI) and rate of production (ROP) analyses on hydrocarbon products were also investigated to identify main reaction pathways and to differentiate among the models. The formation of $\mathrm{C}_{3} \mathrm{H}_{6}$, a minor but important species 
for OCM, was also discussed. The simulation results of selected models were compared against the experimental data and the best model was determined. The main objectives of this work were to examine different gas-phase kinetic models with a $0-\mathrm{D}$ reactor, under methane-rich operating conditions, and to show the essential role of an accurate gas-phase model for developing homogeneous-heterogeneous OCM reaction networks.

\section{RESULTS AND DISCUSSION}

Discussion of Selected Models. Nine models, including AramcoMech3.0, ${ }^{59,60}$ the CRECK model $\left(\mathrm{C}_{0}-\mathrm{C}_{3}\right){ }^{61}$ GRIMech 3.0, ${ }^{62}$ the Karakaya model, ${ }^{31}$ NUIGMech $1.1,{ }^{63}$ the Quiceno model, ${ }^{64}$ the Schwarz model, ${ }^{55}$ the Sun model, ${ }^{26}$ and USC Mech II, ${ }^{65}$ were chosen in this study for gas-phase simulation under OCM conditions, where all the models were reported with experimental validations for either strictly gasphase kinetic studies or heterogeneous catalysis for methane oxidation in fuel-rich conditions (CPO or OCM). General information of all the models is listed in Table 1. All the reaction mechanisms had rates expressed in the form of Arrhenius parameters, as shown in eq 6, where $A$ is the preexponential factor, and $E_{\mathrm{a}}$ is the activation energy.

$$
k=A T^{n} \exp \left(-\frac{E_{\mathrm{a}}}{R T}\right)
$$

Of the chosen models, AramcoMech3.0 was built upon AramcoMech2. $0^{60}$ and AramcoMech $1.3^{66}$ and accurately described the gas-phase kinetics and thermochemical properties of $\mathrm{C}_{0}-\mathrm{C}_{4}$. The model was validated against experimental measurements on hydrocarbon oxidation and pyrolysis $\left(\mathrm{C}_{1}-\right.$ $\mathrm{C}_{4}$-based hydrocarbon and oxygenated fuels). On the other hand, the newly published mechanism NUIGMech $1.1^{63}$ was developed based on experimental and theoretical studies by the National University of Ireland Galway (NUIG), the same team for AramcoMech development. The mechanism was also validated against oxidation of $\mathrm{C}_{1}-\mathrm{C}_{4}$ hydrocarbons and their mixtures. The CRECK model used in this study ${ }^{61}$ was also developed based on AramcoMech2.0 $0^{67}$ and further updated based on experimental validation under MILD and OXY fuel combustion conditions. GRI-Mech $3.0^{62}$ targeted modeling of the combustion of natural gas. USC Mech II $^{65}$ was developed based on different combustion models, including GRI-Mech 3.0. It was also validated against the combustion data of $\mathrm{C}_{0}-$ $\mathrm{C}_{4}$. The model of Schwarz et al. ${ }^{55}$ was adapted and reduced from Dooley's model, ${ }^{68}$ which described the oxidation of methyl formate, and compared it against the experimental data of fuel-rich methane oxidation (OCM condition) in a plug flow reactor. In addition to these four models, from strictly gasphase studies, as discussed above, two other models were selected from homogeneous-heterogeneous networks for methane oxidation in the presence of catalysts. In this study, only the homogeneous models accounted for gas-phase simulation. The model of Karakaya et al. ${ }^{31}$ validated the experimental data for OCM over $\mathrm{Mn} / \mathrm{Na}_{2} \mathrm{WO}_{4} / \mathrm{SiO}_{2}$ against wide temperature ranges and $\mathrm{CH}_{4} / \mathrm{O}_{2}$ ratios in a 1-D adiabatic packed bed reactor; its gas-phase model, taken from Sun et al., $^{26}$ consisted of 39 elementary reactions with 22 gas-phase species with parameter modifications. The model of Sun et $\mathrm{al}^{26}$ consists of homogeneous-heterogeneous reaction networks, which were validated against OCM experimental results with $\mathrm{Li} / \mathrm{MgO}$ and $\mathrm{Sn} / \mathrm{Li} / \mathrm{MgO}$. The gas-phase part was reduced and modified from the model of Chen et al. ${ }^{19}$ The model of Quiceno et al. ${ }^{64}$ captured the trends of partial oxidation of methane (CPO) over Pt gauze and predicted the production of ethane and ethylene from OCM in 3-D flow fields. The homogeneous part of this model was adapted and reduced from the model of total oxidation of $\mathrm{C}_{1}-\mathrm{C}_{4}$ alkanes at high temperatures. ${ }^{69}$

Effect of Temperature. The input parameters for JSR, as well as inlet compositions, temperatures, and calculated residence times used for simulation, are shown in Table 2,

\section{Table 2. Operating Conditions as Model Input Parameters}

\begin{tabular}{ll}
\multicolumn{1}{|c}{ parameter input } & \\
nozzle type & crossed nozzles \\
operating temperature, $T$ & $700-1000{ }^{\circ} \mathrm{C}$ \\
reactor volume & $76 \mathrm{~cm}^{3}$ \\
inlet $\mathrm{CH}_{4} / \mathrm{O}_{2}$ molar ratio & $2-6$ \\
pressure, $P$ & $101 \mathrm{kPa}$ \\
inlet methane concentration & $1-5 \%$, diluted with $\mathrm{N}_{2}$ \\
residence time (RT), $\tau$ & $1000-3000 \mathrm{~ms}$ \\
reactor type & perfectly stirred reactor $(0-\mathrm{D})$ \\
\hline
\end{tabular}

which corresponded to the experimental setup and operating conditions. The temperature effect of gas-phase OCM was studied from 700 to $1000{ }^{\circ} \mathrm{C}$, and the outlet concentration of each main species, including $\mathrm{CH}_{4}, \mathrm{C}_{2} \mathrm{H}_{6}, \mathrm{C}_{2} \mathrm{H}_{4}, \mathrm{CO}, \mathrm{CO}_{2}$, and $\mathrm{O}_{2}$, is measured and plotted against the measured temperature in Figure 1. Simulation results for each model were compared with experimental data. According to the experimental results, methane conversion was initially observed at approximately $860^{\circ} \mathrm{C}$, which corresponded with the results from the previous literature for a low inlet methane concentration in an oxygenrich condition. ${ }^{77}$ From the observations, $\mathrm{C}_{2} \mathrm{H}_{6}$ was produced first at lower temperatures under methane-rich operating conditions than CO. From the trends, the product concentrations all increased with the temperature. For reactant consumption $\left(\mathrm{CH}_{4}\right.$ and $\left.\mathrm{O}_{2}\right)$, by comparing experimental data against the simulation results in Figure 1a,f, USC Mech II, GRI-Mech 3.0, CRECK, NUIGMech1.1, and AramcoMech3.0 successfully followed the trend of reactant consumptions and accurately predicted the concentration profiles against temperature. The Schwarz model also captured the general trend of reactant consumption but slightly overestimated the consumption rate at higher temperatures. For product formation, the simulation results of these four models were also in agreement regarding the measured concentration profiles. In Figure 1b, USC Mech II, GRI-Mech 3.0, CRECK, NUIGMech1.1, and the Schwarz model all captured the local concentration plateau of $\mathrm{C}_{2} \mathrm{H}_{6}$ at $980{ }^{\circ} \mathrm{C}$, while AramcoMech3.0 responded somewhat slower. The Schwarz model overestimated $\mathrm{CO}$ production in Figure $1 \mathrm{~d}$. The CRECK model overestimated $\mathrm{CO}_{2}$ production, whereas USC Mech II underestimated it in Figure le.

Among the gas-phase models taken from homogeneousheterogeneous reaction networks, the Sun model did not show any reactivity under all operating conditions in Table 2 . Therefore, the simulation results are not plotted for comparison with the experimental data. On the other hand, the Karakaya and Quiceno models significantly overestimated the consumption of reactants: Methane and oxygen were heavily consumed at $740{ }^{\circ} \mathrm{C}$ and oxygen was fully consumed at $1000{ }^{\circ} \mathrm{C}$. Because of the overestimated reactant consumptions, 

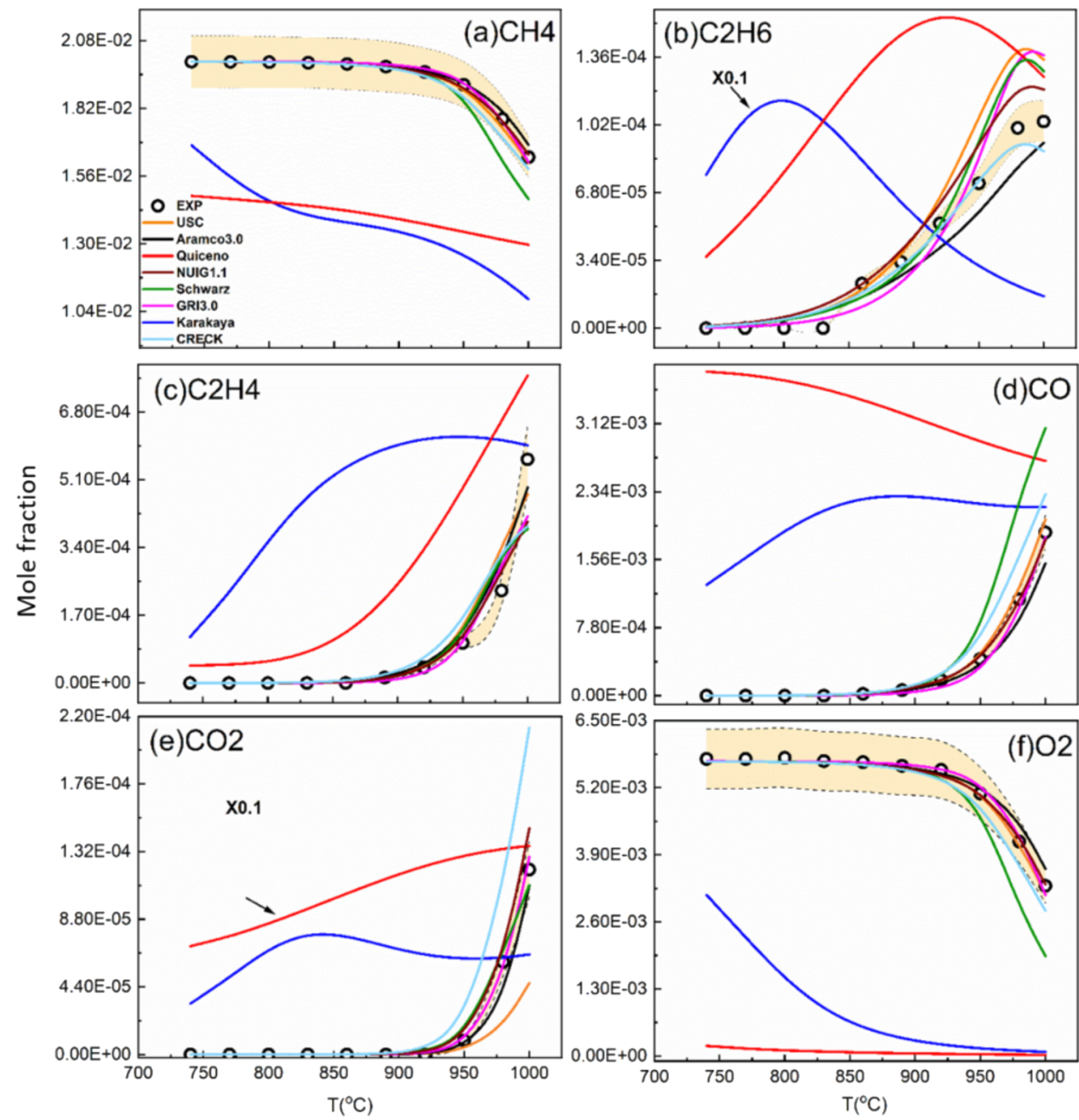

Figure 1. Comparison of mole fraction between experimental (hollow circles) and simulated results (lines with corresponding colors) of (a) $\mathrm{CH}_{4}$, (b) $\mathrm{C}_{2} \mathrm{H}_{6}$, (c) $\mathrm{C}_{2} \mathrm{H}_{4}$, (d) $\mathrm{CO}$, (e) $\mathrm{CO}_{2}$, and (f) $\mathrm{O}_{2}$ in the outlet stream against temperature. Operating condition: $2 \%$ inlet $\mathrm{CH}_{4}, \mathrm{CH}_{4} / \mathrm{O}_{2}=3.5,101$ $\mathrm{kPa}$ total pressure, $\mathrm{N}_{2}$ as balance, and $\mathrm{RT}=2000 \mathrm{~ms}$. Yellow shadowed regions with dotted lines are error bars for experimental data.

the simulations of each model also displayed completely different trends than the experimental results. Overestimations in concentration for each product can be observed in Figure 1. In Figure $1 \mathrm{~b}$, the concentration plateau shifted from $980{ }^{\circ} \mathrm{C}$ to $800{ }^{\circ} \mathrm{C}$ and $920{ }^{\circ} \mathrm{C}$ for the Karakaya and Quiceno models, respectively; for this reason, details of these two models were reviewed to clarify their kinetic pathways. It was found that the gas-phase reactions contributed significantly to the overall homogeneous-heterogeneous network. The homogeneousheterogeneous model from Karakaya et al. ${ }^{31}$ predicted significant amounts of gas-phase species for OCM at temperatures ranging from 600 to $850{ }^{\circ} \mathrm{C}$, with inlet $\mathrm{CH}_{4}$ / $\mathrm{O}_{2}$ ratios of 2,5 , and 10 , respectively, even in the absence of a catalyst bed. On the other hand, Quiceno et al. ${ }^{64}$ studied the catalytic partial oxidation (CPO) of methane by Pt gauze, targeting a temperature range of $1000-1200 \mathrm{~K}\left(727-927^{\circ} \mathrm{C}\right)$ with an inlet $\mathrm{CH}_{4} / \mathrm{O}_{2}$ ratio of 2.5 . Within their targeted temperature range, excessive radicals were reported to be generated and consumed via gas-phase species, such as hydroxyl radicals, which greatly affected the methane conversion in the process. At $750{ }^{\circ} \mathrm{C}$, the gas-phase models of Karakaya and Quiceno already predicted approximately 20 and $25 \%$ of overall methane conversion in Figure 1a, respectively. These results indicated that the gas-phase reaction parts were adjusted based on their experimental observations with the presence of catalysts, which degraded the overall accuracy and physical significance of the gas-phase models. Indeed, because the role of the catalyst surface was studied and reported to be a main contributor to the production and quenching of radicals, ${ }^{18}$ those excessive radicals should have been generated and consumed within the surface networks instead. This supports the theory that the development of a heterogeneous mechanism should be based first on an accurate gas-phase reaction model, but not vice versa. In the later sections, the simulation results from the Karakaya and Quiceno models are not discussed but are still plotted for reference.

Effect of Residence Time and $\mathrm{CH}_{4} / \mathrm{O}_{2}$ Ratio. In addition to investigating the influence of temperature on the gas-phase OCM, the effect of various residence times (RTs) was studied from 1000 to $3000 \mathrm{~ms}(1-3 \mathrm{~s})$. From previous reports in the literature, it was determined that the most suitable residence time for this JSR was $0.5-5 \mathrm{s.}^{57}$ In eq 6 , the total inlet flow rates are adjusted against the reactor temperature to maintain fixed residence times. The temperature was $980{ }^{\circ} \mathrm{C}$, where the gas-phase process was activated with observable profile differences among the models. Figure 2 shows the concentration profile of each main species, measured and plotted against residence time. The conversion of methane and oxygen, 

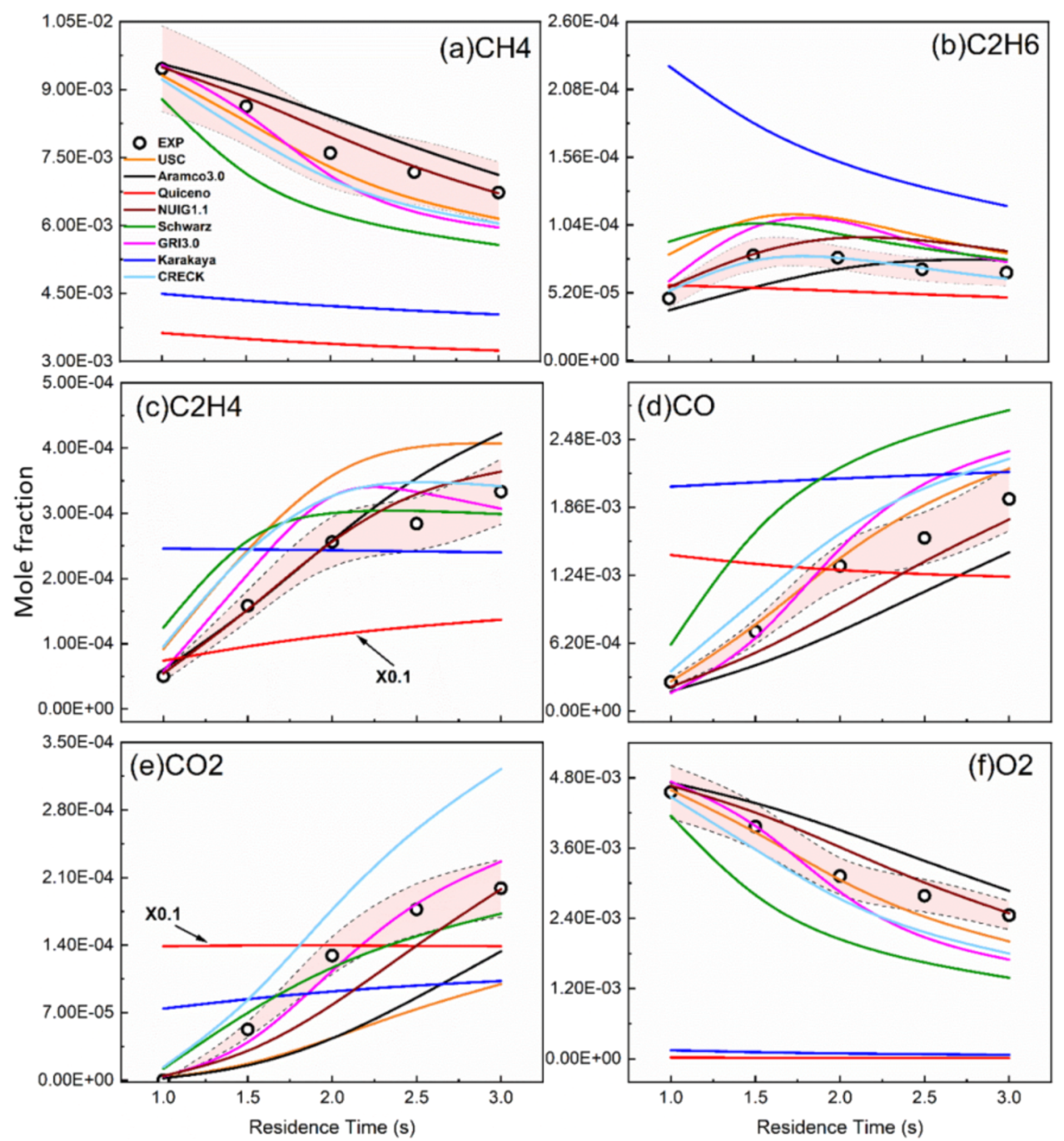

Figure 2. Comparison of mole fraction between experimental (hollow circles) and simulated results (lines with corresponding colors) of (a) $\mathrm{CH}_{4}$, (b) $\mathrm{C}_{2} \mathrm{H}_{6}$, (c) $\mathrm{C}_{2} \mathrm{H}_{4}$, (d) $\mathrm{CO}$, (e) $\mathrm{CO}_{2}$, and (f) $\mathrm{O}_{2}$ in the outlet stream against residence time. Operating condition: $1 \%$ inlet $\mathrm{CH}_{4}, \mathrm{CH}_{4} / \mathrm{O}_{2}=2$, $101 \mathrm{kPa}$ total pressure, $\mathrm{N}_{2}$ as balance, and $T=980{ }^{\circ} \mathrm{C}$. Red shadowed regions with dotted lines represent error bars for experimental data.

as well as the production of $\mathrm{C}_{2} \mathrm{H}_{4}, \mathrm{CO}$, and $\mathrm{CO}_{2}$, increased with residence time; a longer time promoted more reactions within the reactor. However, the concentration of $\mathrm{C}_{2} \mathrm{H}_{6}$ increased until $\mathrm{RT}=1.5 \mathrm{~s}$ and then decreased with higher residence times (Figure $2 \mathrm{~b}$ ). This shows that $\mathrm{C}_{2} \mathrm{H}_{6}$, as the primary product, was formulated mainly at low RTs and then further reacted to other species. In comparison with simulation results against the measured data in Figure 2a,f, USC Mech II, GRI-Mech 3.0, CRECK, NUIGMech1.1, and AramcoMech3.0 successfully captured the trend of reactant consumption and accurately predicted the concentration profiles within a tolerated degree. The Schwarz model once again overestimated the reactant consumption profile. For product formation, the simulation trends of these models generally agreed with the experimental results. USC Mech II, CRECK, GRI-Mech 3.0, and the Schwarz model captured the local concentration maxima of $\mathrm{C}_{2} \mathrm{H}_{6}$ at $\mathrm{RT}=1.5 \mathrm{~s}$. Like the trends of the temperature effect, AramcoMech3.0 showed delayed responses against residence time for the profiles including $\mathrm{C}_{2} \mathrm{H}_{6}, \mathrm{C}_{2} \mathrm{H}_{4}$, and $\mathrm{CO}_{2}$. USC Mech II, GRI-Mech 3.0, and NUIGMech1.1 showed good agreement for $\mathrm{CO}$ production in Figure 2d, whereas the Schwarz model overestimated CO production. On the other hand, USC Mech II and AramcoMech3.0 under- estimated $\mathrm{CO}_{2}$ production, and CRECK overestimated it, while NUIGMech1.1 and GRI-Mech 3.0 predicted it well within the tolerated range.

Furthermore, the $\mathrm{CH}_{4} / \mathrm{O}_{2}$ ratio was an important factor for consideration in the OCM process, apparently affecting the overall methane conversion as well as the selectivity of targeted species. In this study, the $\mathrm{CH}_{4} / \mathrm{O}_{2}$ ratio effect was investigated by varying the inlet oxygen concentrations at a constant methane concentration under the same residence time. The concentration of the main measured products is shown in Figure 3 and compared with simulated concentrations with selected models. From the experimental results, the reactants were barely consumed at high $\mathrm{CH}_{4} / \mathrm{O}_{2}$ ratios (low oxygen inlet concentrations), where sharp reductions in the formation of all products were observed at $\mathrm{CH}_{4} / \mathrm{O}_{2}$ ratios higher than 3.5. The typical OCM process with catalysts often operated under high $\mathrm{CH}_{4} / \mathrm{O}_{2}$ ratios for higher $\mathrm{C}_{2}$ selectivity, indicating the necessity for the development of a surface reaction mechanism based on accurate gas-phase models. In the comparison of experimental and simulation results in Figure 3, USC Mech II, CRECK, GRI-Mech 3.0, AramcoMech3.0, NUIGMech1.1 and the Schwarz model all captured the trend of the sharp formation reduction at the $\mathrm{CH}_{4} / \mathrm{O}_{2}$ ratio of 3.5 , but the 

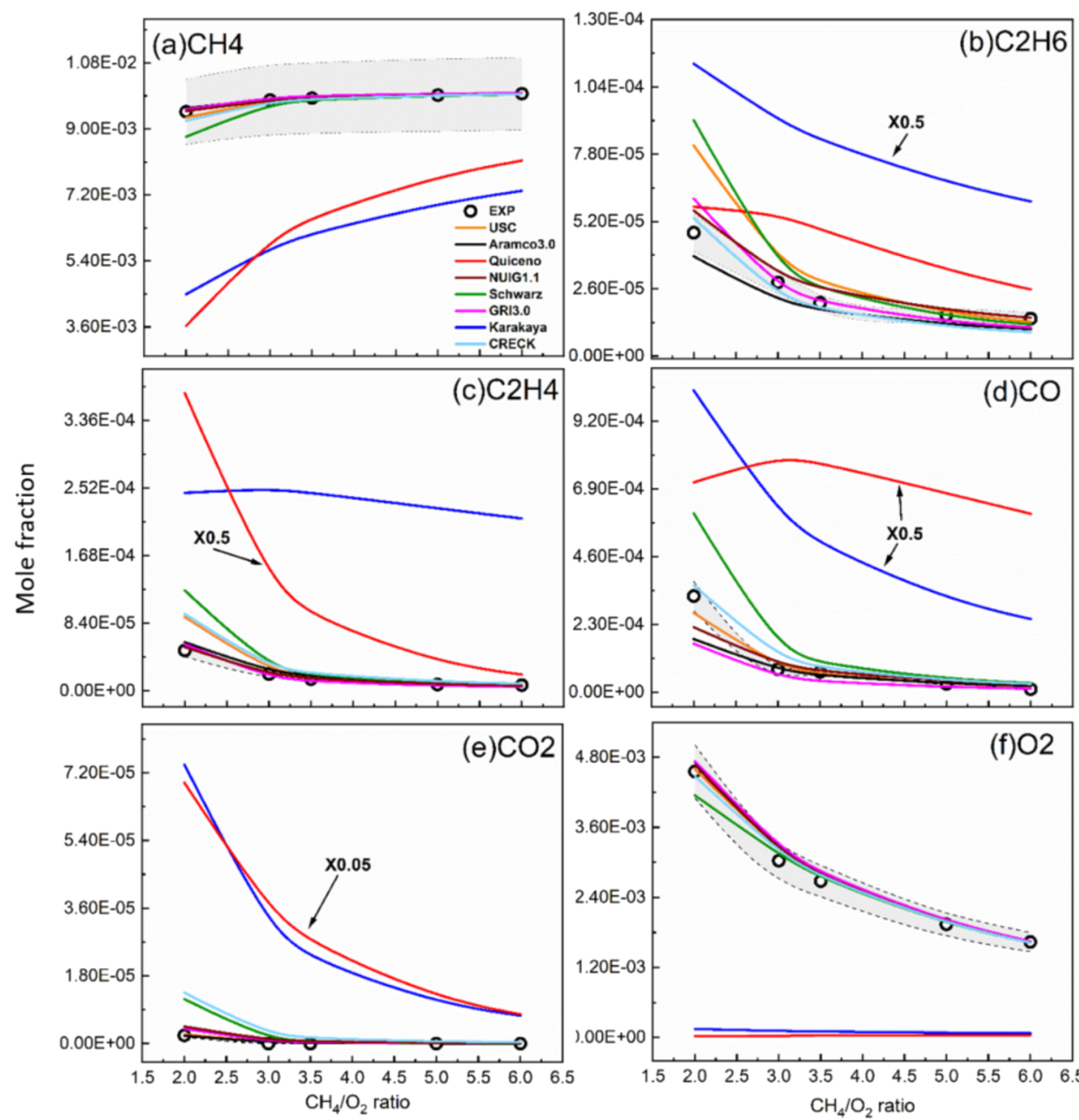

3. Comparison of mole fraction between experimental (hollow circles) and simulated results (lines with corresponding colors) of (a) $\mathrm{CH}_{4}$ (b) $\mathrm{C}_{2} \mathrm{H}_{6}$, (c) $\mathrm{C}_{2} \mathrm{H}_{4}$, (d) $\mathrm{CO}$, (e) $\mathrm{CO}_{2}$, and (f) $\mathrm{O}_{2}$ in the outlet stream against the $\mathrm{CH}_{4} / \mathrm{O}_{2}$ ratio. Operating condition: $1 \%$ inlet $\mathrm{CH}_{4}, 101 \mathrm{kPa}$ total pressure, $\mathrm{N}_{2}$ as balance, $\mathrm{RT}=1000 \mathrm{~ms}$, and $T=980^{\circ} \mathrm{C}$. Gray shadowed regions with dotted lines represent error bars for experimental data.
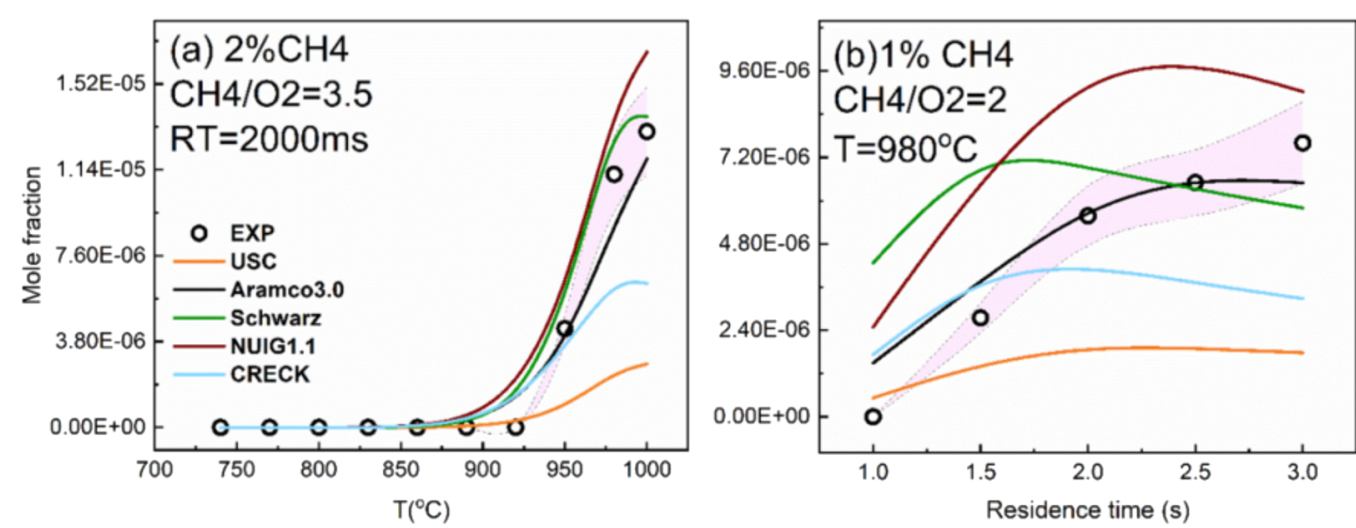

Figure 4. Comparison of mole fraction between experimental (hollow circles) and simulated results (lines with corresponding colors) of $\mathrm{C}_{3} \mathrm{H}_{6}$ in the outlet stream against (a) temperature and (b) $\mathrm{CH}_{4} / \mathrm{O}_{2}$ ratio. Operating conditions are shown in each graph, with $101 \mathrm{kPa}$ total pressure and $\mathrm{N}_{2}$ as balance. Purple shadowed regions with dotted lines represent error bars for experimental data.

reactant consumption and product formation were once again overestimated in the Schwarz model.

Concentration of $\mathrm{C}_{3} \mathrm{H}_{6}$. Unlike other catalytic processes of methane such as $\mathrm{CPO}$ or total oxidation of methane, OCM converts methane into higher hydrocarbons, including $\mathrm{C}_{2}, \mathrm{C}_{3}$, and even $\mathrm{C}_{4}$, under fuel-rich operating conditions. Even though they are considered minority species compared to $\mathrm{C}_{2}$ products, ${ }^{30,35}$ higher hydrocarbons such as $\mathrm{C}_{3} \mathrm{H}_{8}$ and $\mathrm{C}_{3} \mathrm{H}_{6}$ should be included for a comprehensive OCM kinetic model. In this study, minor $\mathrm{C}_{3} \mathrm{H}_{6}$ was experimentally detected, and its concentration profile is plotted against temperature and residence time in Figure 4. Similar trends were observed in 
other products: The formation of $\mathrm{C}_{3} \mathrm{H}_{6}$ increased with temperature as well as residence time. In comparison with the experimental results, USC Mech II and CRECK underestimated the concentration profile of $\mathrm{C}_{3} \mathrm{H}_{6}$ against both temperature and residence time. The description from AramcoMech3.0 agreed well with the experimental data, whereas NUIGMech1.1 captured the trends with slight overestimation. On the other hand, $\mathrm{C}_{3} \mathrm{H}_{6}$ was not included in the mechanism for GRI-Mech 3.0.

Parity diagrams are plotted in Figure 5 to show the overall comparison of simulated results from different models against

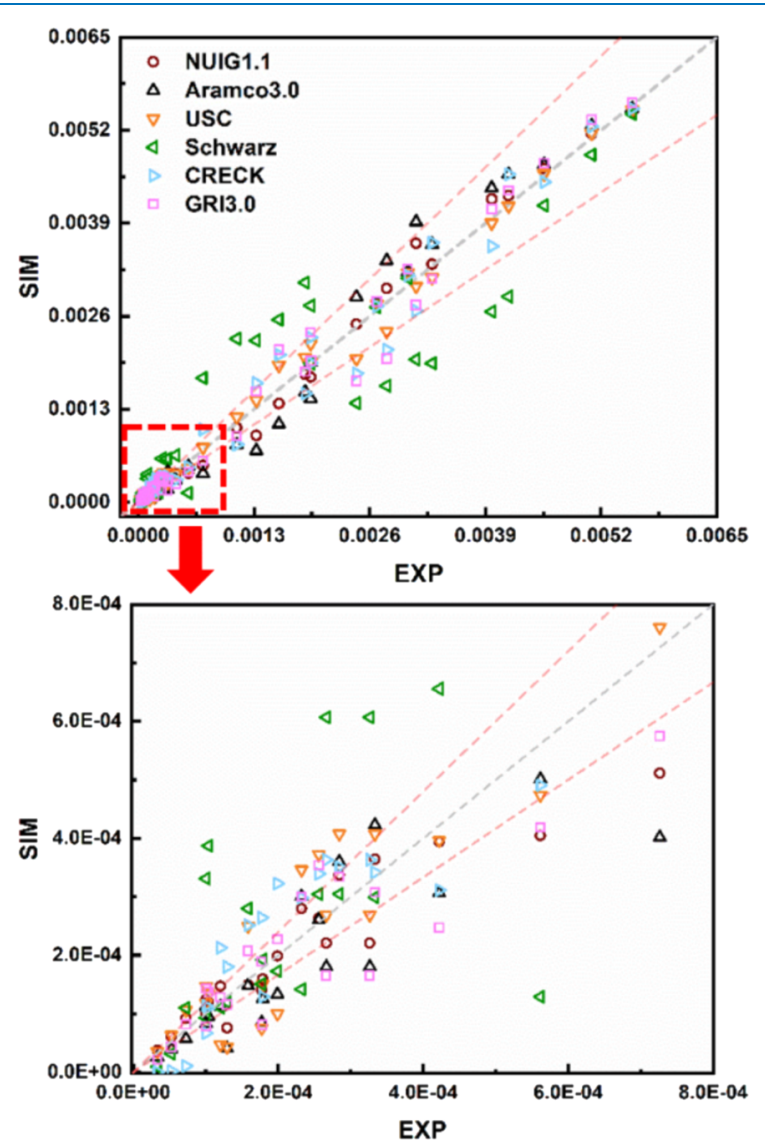

Figure 5. Parity diagrams for main outlet species $\left(\mathrm{O}_{2}, \mathrm{C}_{2} \mathrm{H}_{6}, \mathrm{C}_{2} \mathrm{H}_{4}\right.$, $\mathrm{CO}$, and $\mathrm{CO}_{2}$ ) of different models against experimental results. Simulation results are calculated by the models, each with a corresponding color. Operating conditions are reported in Table 2. The area between red dashed lines is within the $20 \%$ error range of experimental data.

the experimental data under various operating conditions in Table 2. From the comparison, most of the simulated results fit well with the experimental data, except for the Schwarz model for which more outliers could be observed. Other than directly "eyeballing" the analysis, it is better to perform a more quantitative analysis over different models against experimental data. Therefore, quantities of interest (QoI) and traditional rate of production (ROP) analyses were both performed to provide insights and better compare the differences among the models qualitatively.

Qol and ROP Analyses for the Formation of Hydrocarbon Products. The QoI analysis can qualitatively evaluate the difference of reactant or product species profiles between experiment and simulation, while the ROP analysis could identify the key chemical reactions within the kinetic model. By defining different normalized parameters, QoI could well capture the differences within the trend of targeted species profiles, e.g., temperatures and mole fractions at maximum species production or consumption. Also, instead of only targeting a specific reactor temperature for ROP analysis, QoI can evaluate the models across broad temperature ranges. Therefore, both QoI and ROP were implemented, with their own advantages, to complement each other and more thoroughly compare different models in this study.

The parameters for the QoI approach are listed in Table 3, where temperatures and mole fractions are selected based on

Table 3. Definitions of QoI Parameters

\begin{tabular}{|c|c|}
\hline QoI parameter & definition \\
\hline$T_{1}($ in $\mathrm{K})$ & $\begin{array}{l}\text { temperature at } 1 \% \text { consumption of reactant } \\
\text { minimum or production of species maximum }\end{array}$ \\
\hline$T_{50}($ in $\mathrm{K})$ & $\begin{array}{l}\text { temperature at } 50 \% \text { consumption of reactant } \\
\text { minimum or production of species maximum }\end{array}$ \\
\hline$T_{m}($ in $\mathrm{K})$ & $\begin{array}{l}\text { temperature at consumption of reactant } \\
\text { minimum or production of species maximum }\end{array}$ \\
\hline$M_{\mathrm{MF}}$ & $\begin{array}{l}\text { the mole fraction at consumption of reactant } \\
\text { minimum or production of species maximum }\end{array}$ \\
\hline $\mathrm{MS}=1-\frac{T_{1}^{N}}{T_{1}^{E}}$ & $\begin{array}{l}\text { normalized temperature differences at } 1 \% \\
\text { consumption of reactant minimum or } \\
\text { production of species maximum }\end{array}$ \\
\hline $\mathrm{MP}=1-\frac{T_{m}{ }^{N}}{T_{m}^{E}}$ & $\begin{array}{l}\text { normalized temperature differences at } \\
\text { consumption of reactant minimum or } \\
\text { production of species maximum }\end{array}$ \\
\hline$R 50=1-\frac{\left(T_{50}-T_{1}\right)^{N}}{\left(T_{50}-T_{1}\right)^{E}}$ & $\begin{array}{l}\text { normalized temperature slope differences at } 50 \% \\
\text { consumption of reactant minimum or } \\
\text { production of species maximum }\end{array}$ \\
\hline $\mathrm{MMF}=1-\frac{M_{\mathrm{MF}}{ }^{N}}{M_{\mathrm{MF}}^{E}}$ & $\begin{array}{l}\text { normalized mole fraction differences at } \\
\text { consumption of reactant minimum or } \\
\text { production of species maximum }\end{array}$ \\
\hline
\end{tabular}

targeted species profiles. Similar to previous studies, several normalized parameters were determined to describe the difference between experimental and simulation results. ${ }^{78,79}$ MS was considered as the temperature difference at the starting point of production or consumption of each species. The starting point indicates that the initiation reactions occurred to consume reactants and to produce targeted species. The larger absolute values for MS indicate the larger temperature gaps between experiment and simulation at the starting point. To capture the species being produced or consumed, the parameter $R 50$ was introduced to describe the difference in temperature slope at $50 \%$ consumption of reactant minimum or production of species maximum. Positive values of $R 50$ correspond to the higher production or consumption rates of certain species in simulation than measured in experiment, and vice versa. When the targeted species achieve their maximum or minimum, MP and MMF represent the differences in temperature and mole fraction at maximum production or consumption, respectively. Similar to the trends of other parameters, positive values of MP or MMF show the lower maximum temperatures or mole fractions from simulation, and vice versa.

Therefore, Figure 7 shows results of QoI parameters for the key species $\mathrm{CH}_{4}, \mathrm{C}_{2} \mathrm{H}_{6}, \mathrm{C}_{2} \mathrm{H}_{4}, \mathrm{CO}, \mathrm{CO}_{2}$, and $\mathrm{C}_{3} \mathrm{H}_{6}$. For parameters MS and MP, most of values are close to zero for all the models, which indicates that all the models successfully captured the starting point and maximum point over the targeted temperature range. Within this temperature range, the initiation reactions of selected species are well described by all 

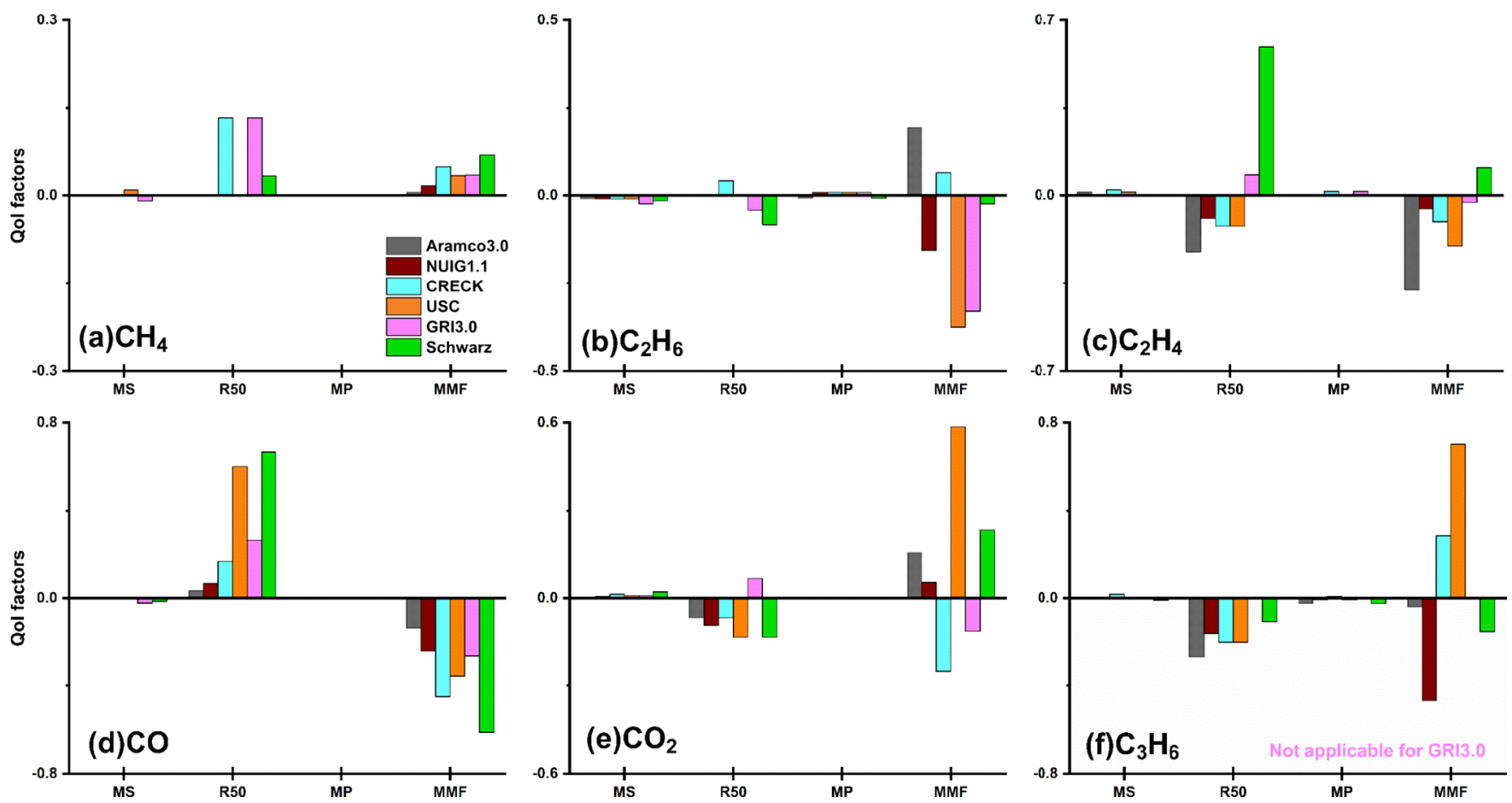

Figure 6. QoI parameter comparison for $\mathrm{CH}_{4}, \mathrm{C}_{2} \mathrm{H}_{6}, \mathrm{C}_{2} \mathrm{H}_{4}, \mathrm{CO}, \mathrm{CO}_{2}$, and $\mathrm{C}_{3} \mathrm{H}_{6}$ among different models. Operating condition: $5 \%$ inlet $\mathrm{CH}_{4}$, 101 $\mathrm{kPa}$ total pressure, $\mathrm{N}_{2}$ as balance, $\mathrm{RT}=2000 \mathrm{~ms}$, and $T_{\max }=1000{ }^{\circ} \mathrm{C}$.

models. On the other hand, due to the fuel-rich nature of operating conditions, some species could not reach their maximum at the highest operating temperature such as $\mathrm{CO}_{x}$, which led to zero values for MP. Indeed, $\mathrm{C}_{2} \mathrm{H}_{6}, \mathrm{C}_{2} \mathrm{H}_{4}$, and $\mathrm{C}_{3} \mathrm{H}_{6}$ reached the maximum from experimental results within the temperature range and $\mathrm{MP}$ values for those species are also nearly zero, which means that the maximum point temperatures are also well predicted.

For the production and consumption rates represented by $R 50$, all models showed good predictions for $\mathrm{C}_{2} \mathrm{H}_{6}$. The CRECK model and GRI-Mech 3.0 overestimated the consumption rate of methane in Figure 6a. The Schwarz model greatly overestimated the production rate of $\mathrm{C}_{2} \mathrm{H}_{4}$ and $\mathrm{CO}$ and underestimated the production rate of $\mathrm{C}_{2} \mathrm{H}_{6}$, which might suggest the faster reaction rates of dehydrogenation reactions from $\mathrm{C}_{2} \mathrm{H}_{6}$ to $\mathrm{C}_{2} \mathrm{H}_{4}$ to a further oxidation process in the model. USC Mech II also greatly overestimated the $\mathrm{CO}$ production rate. On the other hand, for the maximum or minimum mole fractions of each species MMF, the minimum mole fractions of methane were well predicted by all the models. The maximum mole fractions of $\mathrm{C}_{2} \mathrm{H}_{6}$ were overpredicted by NUIGMech1.1, USC Mech II, and GRI-Mech 3.0 and underpredicted by AramcoMech3.0, while the maximum mole fractions of $\mathrm{C}_{2} \mathrm{H}_{4}$ were overestimated by AramcoMech3.0 and USC Mech II. For CO, all the models overestimated the maximum mole fraction. Because of the fuel-rich operating conditions, the parameters of $\mathrm{CH}_{4}, \mathrm{C}_{2} \mathrm{H}_{6}, \mathrm{C}_{2} \mathrm{H}_{4}$, and $\mathrm{CO}$ are primarily considered for the best model selection since they are formed or consumed in larger quantities than other species. By considering the primary parameters from QoI analysis, CRECK, NUIGMech1.1, and AramcoMech3.0 are among the models that fit the best against experimental data. By further comparing the absolute values of these parameters, NUIGMech1.1 is selected as the most comprehensively validated for the OCM gas-phase mechanism. Due to the large data set (species and reactions), NUIGMech1.1 should be further reduced to improve the simulation premise, on the premises that the reduced model should keep the overall accuracy and physical significance.

To investigate the key reaction pathways for reactant consumption and product formation, a rate of production (ROP) analysis was performed with hydrocarbon products, as shown in Figure 7. This overall reaction pathway is similar to

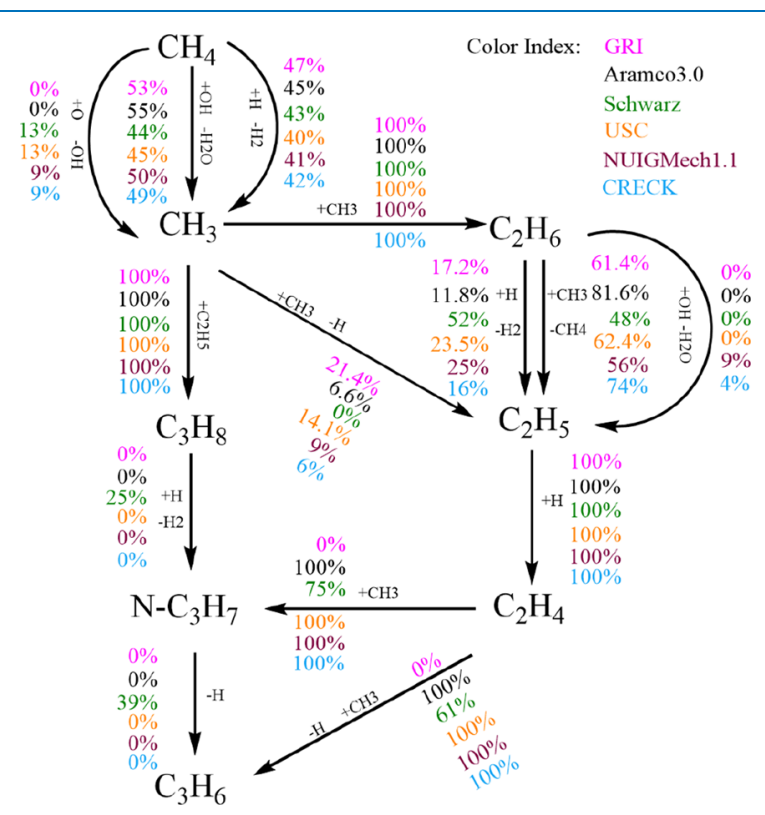

Figure 7. Main reaction pathways for selected gas-phase models on targeted hydrocarbons at $980{ }^{\circ} \mathrm{C}$. Consumption or production percentages shown with corresponding colors. Operating condition: $2 \%$ inlet $\mathrm{CH}_{4}, \mathrm{CH}_{4} / \mathrm{O}_{2}=3.5,101 \mathrm{kPa}$ total pressure, $\mathrm{N}_{2}$ as balance, and $\mathrm{RT}=2000 \mathrm{~ms}$ at the steady state. 
Scheme 1. Schematic of the Experimental Setup in This Study

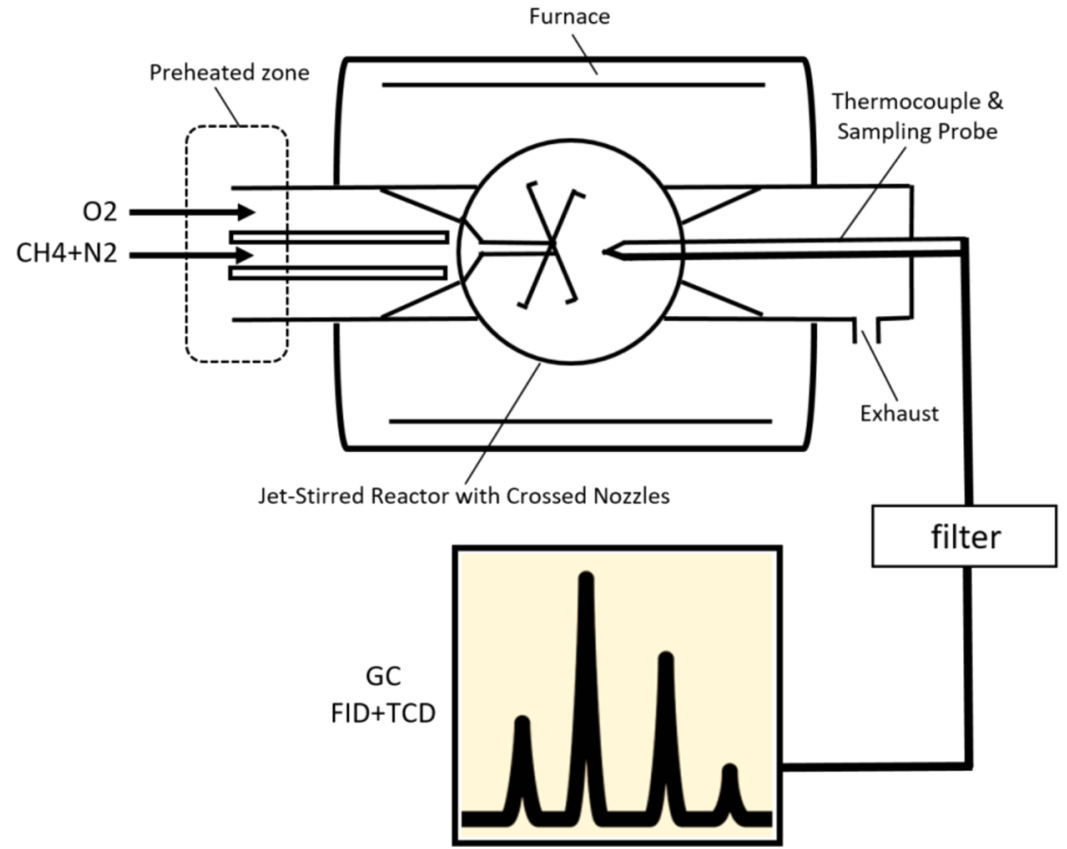

the one previously reported from isotopic studies over gasphase radicals. ${ }^{17}$ All simulations were performed under identical operating conditions. Some common features were observed among the models (Figure 7): The formation of the methyl radical $\mathrm{CH}_{3}$ was essential for any methane conversion in which all the methane was converted to $\mathrm{CH}_{3}$ first via different paths of dehydrogenation, ethane was formulated from the recombination of the methyl radicals $\left(\mathrm{CH}_{3}+\mathrm{CH}_{3}=\right.$ $\mathrm{C}_{2} \mathrm{H}_{6}$ ), ethylene was also generated via the dehydrogenation of ethyl radicals $\left(\mathrm{C}_{2} \mathrm{H}_{5}=\mathrm{C}_{2} \mathrm{H}_{4}+\mathrm{H}\right)$, and propane was produced from the recombination between methyl and ethyl radicals $\left(\mathrm{C}_{2} \mathrm{H}_{5}+\mathrm{CH}_{3}=\mathrm{C}_{3} \mathrm{H}_{8}\right)$. However, different pathways were also observed among the models, which could result in different product concentration profiles. GRI-Mech 3.0 did not include $\mathrm{C}_{3}$ reaction pathways, except for $\mathrm{C}_{3} \mathrm{H}_{8}$. The Schwarz model highlighted dehydrogenation chain reactions from $\mathrm{C}_{3} \mathrm{H}_{8}$ to $\mathrm{N}$ $\mathrm{C}_{3} \mathrm{H}_{7}$ and from $\mathrm{N}-\mathrm{C}_{3} \mathrm{H}_{7}$ to $\mathrm{C}_{3} \mathrm{H}_{6}$, whereas USC Mech II, NUIGMech1.1, CRECK, and AramcoMech3.0 clarified that $\mathrm{C}_{2} \mathrm{H}_{4}+\mathrm{CH}_{3}$ contributed $100 \%$ to the source of $\mathrm{N}-\mathrm{C}_{3} \mathrm{H}_{7}$ and $\mathrm{C}_{3} \mathrm{H}_{6}$. On the other hand, the pathways for the ethyl radical $\mathrm{C}_{2} \mathrm{H}_{5}$, an important intermediate, were different among the models. In Figure 7, $\mathrm{C}_{2} \mathrm{H}_{5}$ was generated from either hydrogen abstraction from $\mathrm{C}_{2} \mathrm{H}_{6}$ by $\mathrm{H}$ or $\mathrm{CH}_{3}$ radicals or via $\mathrm{CH}_{3}$ recombination with simultaneous hydrogen elimination. In all the models, the major source of $\mathrm{C}_{2} \mathrm{H}_{6}$ is via methyl radical recombination.

\section{CONCLUSIONS}

This study experimentally conducted a gas-phase study under OCM conditions in a jet-stirred reactor ( $0-\mathrm{D}$ reactor); simulations were also performed with nine selected gas-phase kinetic models. Various operating parameters, including temperatures, residence times, and inlet $\mathrm{CH}_{4} / \mathrm{O}_{2}$ ratios, were investigated for this comprehensive study. Comparing experimental and simulation results, AramcoMech3.0, the CRECK model, NUIGMech1.1, GRI-Mech 3.0, the Schwarz model, and USC Mech II successfully captured the trends under different operating conditions for OCM. In contrast, the
Sun model, Karakaya model, and Quiceno model, the models adopted from the catalytic process, barely followed the experimental trends, indicating that their gas-phase kinetics were modified based on observations from a coupled heterogeneous network. By performing QoI analysis, all the models were evaluated against experimental results and NUIGMech1.1 was found to be the best model to describe OCM gas-phase kinetics, including the formation of $\mathrm{C}_{3}$ species. For an accurate OCM model, a heterogeneous mechanism should be developed based on an accurate gas-phase reaction model, and NUIGMech1.1 is recommended as the gas-phase model for future heterogeneous model construction.

\section{EXPERIMENTAL AND SIMULATION METHODS}

This study employed a jet-stirred reactor (JSR) to investigate OCM gas-phase kinetics, similar to previous works by this group. $^{80,81}$ Detailed descriptions of JSR are available in the published literature. ${ }^{82,83}$ The schematic of the experimental setup is shown in Scheme 1. Briefly, a spherical reactor with a total volume of $76 \mathrm{~cm}^{3}$ is made of fused silica to minimize wallcatalyzed reactions between the wall and the intermediate species. Four crossed nozzles within the reactor (I.D. of 0.3 $\mathrm{mm}$ ) create stirring jet flows and ideal mixing of the inlet streams. From a previous study, ${ }^{57}$ a JSR with crossed nozzles with inner diameters greater than $0.2 \mathrm{~mm}$ (I.D. $>0.2 \mathrm{~mm}$ ) allow for better mixing. A suitable range of residence time $(0.5-5 \mathrm{~s})$ was carefully selected, corresponding to the reactor volume with crossed nozzles. Ideal mixing assumptions are valid under these geometrical and operation conditions. Nitrogen was selected as the carrier gas and diluent, cofeeding with methane and oxygen as the inlet stream. The inlet methane and oxygen were preheated and introduced separately through different channels so that no reaction would occur before the nozzle injection. The JSR was heated by a furnace to the target temperature, and a K-type thermocouple was located in a thin silica tube to avoid catalytic effects and placed inside the reactor to monitor the reaction temperature. To maintain fixed residence times, the gas flow rates were adjusted based on 
the measured reactor temperature and controlled by MKS mass flow controllers. The temperature homogeneity within the reactor was tested with a pure nitrogen flow and showed good uniformity $\left(<3{ }^{\circ} \mathrm{C} / \mathrm{cm}\right)$. The outlet stream was then sampled by a sonic-throat gas sampling probe connected to a mechanical pump to create a pressure drop that prevented further reactions of the outlets. The sampled gas was analyzed using an Agilent refinery gas analyzer (RGA). The carbon balance (average of 95\%) under each operating condition is calculated and reported in the Supporting Information.

Simulations of the JSR were performed using the perfectlystirred reactor module (PSR) in CHEMKIN-PRO. ${ }^{84}$ The reactor was modeled as zero-dimensional (0-D), with an end time of $50 \mathrm{~s}$ of the transient solver to achieve steady-state criteria. Because of the significant temperature homogeneity and negligible temperature profile along the reactor, the reactor model was set as isothermal. The input inlet compositions, temperatures, and calculated residence times in simulation corresponded to the operating conditions in the experiment in Table 2. The residence time $\tau$ is calculated in eq 7 , where $\rho$ is the mass density, which is related to the pressure and temperature, $V$ is the volume of reactor, and $\dot{m}$ is the mass flow rate of the inlet stream.

$$
\tau=\rho V / \dot{m}
$$

\section{ASSOCIATED CONTENT}

\section{(3) Supporting Information}

The Supporting Information is available free of charge at https://pubs.acs.org/doi/10.1021/acsomega.1c05020.

Details of carbon balance calculations under each reported operating condition (PDF)

\section{AUTHOR INFORMATION}

\section{Corresponding Authors}

Haoyi Wang - Clean Combustion Research Center (CCRC), Physical Sciences and Engineering Division and KAUST Catalysis Center (KCC), Physical Sciences and Engineering Division, King Abdullah University of Science and Technology (KAUST), Thuwal 23955-6900, Saudi Arabia; ○ orcid.org/0000-0002-6865-0646; Email: haoyi.wang@ kaust.edu.sa

S. Mani Sarathy - Clean Combustion Research Center (CCRC), Physical Sciences and Engineering Division and KAUST Catalysis Center (KCC), Physical Sciences and Engineering Division, King Abdullah University of Science and Technology (KAUST), Thuwal 23955-6900, Saudi Arabia; (1) orcid.org/0000-0002-3975-6206;

Email: mani.sarathy@kaust.edu.sa

\section{Authors}

Can Shao - Clean Combustion Research Center (CCRC), Physical Sciences and Engineering Division, King Abdullah University of Science and Technology (KAUST), Thuwal 23955-6900, Saudi Arabia

Jorge Gascon - KAUST Catalysis Center (KCC), Physical Sciences and Engineering Division, King Abdullah University of Science and Technology (KAUST), Thuwal 23955-6900, Saudi Arabia; (i) orcid.org/0000-0001-7558-7123

Kazuhiro Takanabe - Department of Chemical System Engineering, School of Engineering, The University of Tokyo, Bunkyo-ku, Tokyo 113-8656, Japan; Japan Science and
Technology Agency (JST), PRESTO, Kawaguchi, Saitama 332-0012, Japan; 이이이.org/0000-0001-5374-9451

Complete contact information is available at:

https://pubs.acs.org/10.1021/acsomega.1c05020

\section{Notes}

The authors declare no competing financial interest.

\section{ACKNOWLEDGMENTS}

The work at King Abdullah University of Science and Technology (KAUST) is supported by the Office of Sponsored Research with funding from the Clean Combustion Research Center and KAUST Catalysis Center.

\section{REFERENCES}

(1) Keller, G. E.; Bhasin, M. M. Synthesis of ethylene via oxidative coupling of methane: I Determination of active catalysts. J. Catal. 1982, 73, 9-19.

(2) Wu, X. Y.; Tang, Z.; Zhao, X.; Luo, X.; Pennycook, S. J.; Wang, S. L. Visible-light driven room-temperature coupling of methane to ethane by atomically dispersed Au on WO3. J. Energy Chem. 2021, 61, 195-202.

(3) Sato, A.; Ogo, S.; Kamata, K.; Takeno, Y.; Yabe, T.; Yamamoto, T.; Matsumura, S.; Hara, M.; Sekine, Y. Ambient-temperature oxidative coupling of methane in an electric field by a cerium phosphate nanorod catalyst. Chem. Commun. 2019, 55, 4019-4022.

(4) Schammel, W. P.; Wolfenbarger, J.; Ajinkya, M.; McCarty, J.; Cizeron, J. M.; Weinberger, S.; Edwards, J. D.; Sheridan, D.; Scher, E. C.; McCormick, J. Oxidative coupling of methane systems and methods. U.S. Patent No. 9,556,086 B2, 2017.

(5) Cizeron, J.; Radaelli, G.; Lakhapatri, S.; Freer, E.; Hong, J. K.; McCormick, J.; Sheridan, D.; Reid, C.; Pellizzari, R.; Weinberger, S. Reactors and systems for oxidative coupling of methane. U.S. Patent No. 10,047,020, 2018.

(6) Lunsford, J. H. Catalytic conversion of methane to more useful chemicals and fuels: a challenge for the 21 st century. Catal. Today 2000, 63, 165-174.

(7) Pak, S.; Qiu, P.; Lunsford, J. H. Elementary reactions in the oxidative coupling of methane over $\mathrm{Mn} / \mathrm{Na} 2 \mathrm{WO} 4 / \mathrm{SiO} 2$ and $\mathrm{Mn} /$ $\mathrm{Na} 2 \mathrm{WO} 4 / \mathrm{MgO}$ catalysts. J. Catal. 1998, 179, 222-230.

(8) Takanabe, K.; Iglesia, E. Mechanistic Aspects and Reaction Pathways for Oxidative Coupling of Methane on $\mathrm{Mn} / \mathrm{Na} 2 \mathrm{WO} 4 / \mathrm{SiO} 2$ Catalysts. J. Phys. Chem. C 2009, 113, 10131-10145.

(9) Karakaya, C.; Kee, R. J. Progress in the direct catalytic conversion of methane to fuels and chemicals. Prog. Energy Combust. Sci. 2016, 55, 60-97.

(10) Lomonosov, V. I.; Sinev, M. Y. Oxidative coupling of methane: Mechanism and kinetics. Kinet. Catal. 2016, 57, 647-676.

(11) Kiani, D.; Sourav, S.; Baltrusaitis, J.; Wachs, I. E. Oxidative Coupling of Methane (OCM) by SiO2-Supported Tungsten Oxide Catalysts Promoted with $\mathrm{Mn}$ and Na. ACS Catal. 2019, 9, 59125928.

(12) Takanabe, K.; Iglesia, E. Rate and selectivity enhancements mediated by $\mathrm{OH}$ radicals in the oxidative coupling of methane catalyzed by $\mathrm{Mn} / \mathrm{Na} 2 \mathrm{WO} 4 / \mathrm{SiO} 2$. Angew. Chem., Int. Ed. 2008, 47, 7689-7693.

(13) Al-Zahrani, S. M. S.; Lobban, L. L. Effects of Steam and Liquid Water Treatment on the Oxidative Coupling of Methane over a Li/ $\mathrm{MgO}$ Catalyst. Ind. Eng. Chem. Res. 1995, 34, 1060-1073.

(14) Takanabe, K.; Khan, A. M.; Tang, Y.; Nguyen, L.; Ziani, A.; Jacobs, B. W.; Elbaz, A. M.; Sarathy, S. M.; Tao, F. F. Integrated In Situ Characterization of a Molten Salt Catalyst Surface: Evidence of Sodium Peroxide and Hydroxyl Radical Formation. Angew. Chem., Int. Ed. 2017, 56, 10403-10407.

(15) Li, D.; Baslyman, W. S.; Sarathy, S. M.; Takanabe, K. Impact of $\mathrm{OH}$ Radical Generator Involvement in the Gas-Phase Radical 
Reaction Network on the Oxidative Coupling of Methane-A Simulation Study. Energy Technol. 2020, 8, 1900563.

(16) Shi, C.; Hatano, M.; Lunsford, J. H. A Kinetic-Model for the Oxidative Coupling of Methane over Li+/Mgo Catalysts. Catal. Today 1992, 13, 191-199.

(17) Mims, C. A.; Mauti, R.; Dean, A. M.; Rose, K. D. Radical Chemistry in Methane Oxidative Coupling - Tracing of Ethylene Secondary Reactions with Computer-Models and Isotopes. J. Phys Chem.. 1994, 98, 13357-13372.

(18) Couwenberg, P. M.; Chen, Q.; Marin, G. B. Kinetics of a gasphase chain reaction catalyzed by a solid: The oxidative coupling of methane over Li/MgO-based catalysts. Ind. Eng. Chem. Res. 1996, 35, 3999-4011.

(19) Chen, Q.; Couwenberg, P. M.; Marin, G. B. Effect of Pressure on the Oxidative Coupling of Methane in the Absence of Catalyst. AIChE J. 1994, 40, 521-535.

(20) Alexiadis, V. I.; Chaar, M.; van Veen, A.; Muhler, M.; Thybaut, J. W.; Marin, G. B. Quantitative screening of an extended oxidative coupling of methane catalyst library. Appl. Catal., B 2016, 199, 252259.

(21) Alexiadis, V. I.; Thybaut, J. W.; Kechagiopoulos, P. N.; Chaar, M.; Van Veen, A. C.; Muhler, M.; Marin, G. B. Oxidative coupling of methane: catalytic behaviour assessment via comprehensive microkinetic modelling. Appl. Catal., B 2014, 150-151, 496-505.

(22) Kechagiopoulos, P. N.; Thybaut, J. W.; Marin, G. B. Oxidative Coupling of Methane: A Microkinetic Model Accounting for Intraparticle Surface-Intermediates Concentration Profiles. Ind. Eng. Chem. Res. 2013, 53, 1825-1840.

(23) Pirro, L.; Mendes, P. S. F.; Paret, S.; Vandegehuchte, B. D.; Marin, G. B.; Thybaut, J. W. Descriptor-property relationships in heterogeneous catalysis: exploiting synergies between statistics and fundamental kinetic modelling. Catal. Sci. Technol. 2019, 9, 31093125 .

(24) Pirro, L.; Mendes, P. S. F.; Vandegehuchte, B. D.; Marin, G. B.; Thybaut, J. W. Catalyst screening for the oxidative coupling of methane: from isothermal to adiabatic operation via microkinetic simulations. React. Chem. Eng. 2020, 5, 584-596.

(25) Pirro, L.; Obradović, A.; Vandegehuchte, B. D.; Marin, G. B.; Thybaut, J. W. Model-Based Catalyst Selection for the Oxidative Coupling of Methane in an Adiabatic Fixed-Bed Reactor. Ind. Eng. Chem. Res. 2018, 57, 16295-16307.

(26) Sun, J.; Thybaut, J.; Marin, G. Microkinetics of methane oxidative coupling. Catal. Today 2008, 137, 90-102.

(27) Thybaut, J. W.; Sun, J.; Olivier, L.; Van Veen, A. C.; Mirodatos, C.; Marin, G. B. Catalyst design based on microkinetic models: Oxidative coupling of methane. Catal. Today 2011, 159, 29-36.

(28) Vandewalle, L. A.; Lengyel, I.; West, D. H.; Van Geem, K. M.; Marin, G. B. Catalyst ignition and extinction: A microkinetics-based bifurcation study of adiabatic reactors for oxidative coupling of methane. Chem. Eng. Sci. 2019, 199, 635-651.

(29) Vandewalle, L. A.; Van de Vijver, R.; Van Geem, K. M.; Marin, G. B. The role of mass and heat transfer in the design of novel reactors for oxidative coupling of methane. Chem. Eng. Sci. 2019, 198, $268-289$.

(30) Karakaya, C.; Zhu, H.; Zohour, B.; Senkan, S.; Kee, R. J. Detailed Reaction Mechanisms for the Oxidative Coupling of Methane over $\mathrm{La} 2 \mathrm{O} 3 / \mathrm{CeO} 2 \mathrm{Nanofiber}$ Fabric Catalysts. ChemCatChem 2017, 9, 4538-4551.

(31) Karakaya, C.; Zhu, H.; Loebick, C.; Weissman, J. G.; Kee, R. J. A detailed reaction mechanism for oxidative coupling of methane over $\mathrm{Mn} / \mathrm{Na} 2 \mathrm{WO} 4 / \mathrm{SiO} 2$ catalyst for non-isothermal conditions. Catal. Today 2018, 312, 10-22.

(32) Chen, Q.; Hoebink, J. H. B. J.; Marin, G. B. Kinetics of the Oxidative Coupling of Methane at Atmospheric-Pressure in the Absence of Catalyst. Ind. Eng. Chem. Res. 1991, 30, 2088-2097.

(33) Sekine, Y.; Nishimura, T.; Fujimoto, K. Oxidative coupling of methane in the gas phase: Simulation and reaction mechanism. Energy Fuels 1998, 12, 828-829.
(34) Zanthoff, H.; Baerns, M. Oxidative Coupling of Methane in the Gas-Phase. Kinetic Simulation and Experimental-Verification. Ind. Eng. Chem. Res. 1990, 29, 2-10.

(35) Luo, L.; You, R.; Liu, Y.; Yang, J.; Zhu, Y.; Wen, W.; Pan, Y.; Qi, F.; Huang, W. Gas-Phase Reaction Network of Li/MgO-Catalyzed Oxidative Coupling of Methane and Oxidative Dehydrogenation of Ethane. ACS Catal. 2019, 9, 2514-2520.

(36) Ishioka, S.; Miyazato, I.; Takahashi, L.; Nguyen, T. N.; Taniike, T.; Takahashi, K. Unveiling gas-phase oxidative coupling of methane via data analysis. J. Comput. Chem. 2021, 42, 1447-1451.

(37) Takanabe, K. Catalytic Conversion of Methane: Carbon Dioxide Reforming and Oxidative Coupling. J. Jpn. Pet. Inst. 2012, 55, $1-12$.

(38) Liang, Y.; Li, Z.; Nourdine, M.; Shahid, S.; Takanabe, K. Methane Coupling Reaction in an Oxy-Steam Stream through an $\mathrm{OH}$ Radical Pathway by using Supported Alkali Metal Catalysts. Chem CatChem 2014, 6, 1245-1251.

(39) Fleischer, V.; Steuer, R.; Parishan, S.; Schomäcker, R. Investigation of the surface reaction network of the oxidative coupling of methane over $\mathrm{Na} 2 \mathrm{WO} 4 / \mathrm{Mn} / \mathrm{SiO} 2$ catalyst by temperature programmed and dynamic experiments. J. Catal. 2016, 341, 91-103.

(40) Kalenik, Z.; Wolf, E. E. Transient And Isotopic Studies Of The Oxygen Transport And Exchange During Oxidative Coupling Of Methane On Sr Promoted La2o3. Catal. Lett. 1991, 9, 441-449.

(41) Lacombe, S.; Zanthoff, H.; Mirodatos, C. Oxidative Coupling of Methane over Lanthana Catalysts. 2. A Mechanistic Study Using Isotope Transient Kinetics. J. Catal. 1995, 155, 106-116.

(42) Shi, C.; Xu, M.; Rosynek, M. P.; Lunsford, J. H. Origin of kinetic isotope effects during the oxidative coupling of methane over a lithium(1+)/magnesia catalyst. J. Phys. Chem. 1993, 97, 216-222.

(43) Ishikawa, A.; Tateyama, Y. A First-Principles Microkinetics for Homogeneous-Heterogeneous Reactions: Application to Oxidative Coupling of Methane Catalyzed by Magnesium Oxide. ACS Catal. 2021, 11, 2691-2700.

(44) Wang, S.; Cong, L.; Zhao, C.; Li, Y.; Pang, Y.; Zhao, Y.; Li, S.; Sun, Y. First principles studies of $\mathrm{CO} 2$ and $\mathrm{O} 2$ chemisorption on La2O3 surfaces. Phys. Chem. Chem. Phys. 2017, 19, 26799-26811.

(45) Lei, Y.; Chu, C.; Li, S.; Sun, Y. Methane Activations by Lanthanum Oxide Clusters. J. Phys. Chem. C 2014, 118, 7932-7945.

(46) Chu, C.; Zhao, Y.; Li, S.; Sun, Y. Role of Peroxides on La2O3 Catalysts in Oxidative Coupling of Methane. J. Phys. Chem. C 2014, 118, 27954-27960.

(47) Chu, C.; Zhao, Y.; Li, S.; Sun, Y. Correlation between the acidbase properties of the $\mathrm{La} 2 \mathrm{O} 3$ catalyst and its methane reactivity. Phys. Chem. Chem. Phys. 2016, 18, 16509-16517.

(48) Palmer, M. S.; Neurock, M.; Olken, M. M. Periodic Density Functional Theory Study of Methane Activation over La2O3: Activity of O2-, O-, O22-, Oxygen Point Defect, and Sr2+-Doped Surface Sites. J. Am. Chem. Soc. 2002, 124, 8452-8461.

(49) Studt, F.; Sharafutdinov, I.; Abild-Pedersen, F.; Elkjær, C. F.; Hummelshøj, J. S.; Dahl, S.; Chorkendorff, I.; Nørskøv, J. K. Discovery of a Ni-Ga catalyst for carbon dioxide reduction to methanol. Nat. Chem. 2014, 6, 320-324.

(50) Schwach, P.; Pan, X.; Bao, X. Direct Conversion of Methane to Value-Added Chemicals over Heterogeneous Catalysts: Challenges and Prospects. Chem. Rev. 2017, 117, 8497-8520.

(51) Cong, L.; Zhao, Y.; Li, S.; Sun, Y. Sr-doping effects on La 2 O 3 catalyst for oxidative coupling of methane. Chin. J. Catal. 2017, 38, 899-907.

(52) Kumar, G.; Lau, S. L. J.; Krcha, M. D.; Janik, M. J. Correlation of Methane Activation and Oxide Catalyst Reducibility and Its Implications for Oxidative Coupling. ACS Catal. 2016, 6, 1812-1821. (53) Jiang, T.; Song, J.; Huo, M.; Yang, N.; Liu, J.; Zhang, J.; Sun, Y.; $\mathrm{Zhu}, \mathrm{Y}$. La2O3 catalysts with diverse spatial dimensionality for oxidative coupling of methane to produce ethylene and ethane. RSC Adv. 2016, 6, 34872-34876.

(54) Hou, Y.-H.; Han, W.-C.; Xia, W.-S.; Wan, H.-L. Structure Sensitivity of $\mathrm{La}_{2} \mathrm{O} 2 \mathrm{CO} 3$ Catalysts in the Oxidative Coupling of Methane. ACS Catal. 2015, 5, 1663-1674. 
(55) Schwarz, H.; Geske, M.; Franklin Goldsmith, C.; Schlögl, R.; Horn, R. Fuel-rich methane oxidation in a high-pressure flow reactor studied by optical-fiber laser-induced fluorescence, multi-species sampling profile measurements and detailed kinetic simulations. Combust. Flame 2014, 161, 1688-1700.

(56) Monge, F.; Aranda, V.; Millera, A.; Bilbao, R.; Alzueta, M. U. Tubular Flow Reactors. In Cleaner Combustion: Developing Detailed Chemical Kinetic Models; Battin-Leclerc, F.; Simmie, J. M.; Blurock, E. Eds. Springer London: London, 2013; pp. 211-230.

(57) Ayass, W. W.; Nasir, E. F.; Farooq, A.; Sarathy, S. M. Mixingstructure relationship in jet-stirred reactors. Chem. Eng. Res. Des. 2016, 111, 461-464.

(58) Herbinet, O.; Dayma, G. Jet-Stirred Reactors. In Cleaner Combustion: Developing Detailed Chemical Kinetic Models; BattinLeclerc, F.; Simmie, J. M.; Blurock, E. Eds. Springer London: London, 2013; pp. 183-210.

(59) Zhou, C.-W.; Li, Y.; Burke, U.; Banyon, C.; Somers, K. P.; Ding, S.; Khan, S.; Hargis, J. W.; Sikes, T.; Mathieu, O.; Petersen, E. L.; AlAbbad, M.; Farooq, A.; Pan, Y.; Zhang, Y.; Huang, Z.; Lopez, J.; Loparo, Z.; Vasu, S. S.; Curran, H. J. An experimental and chemical kinetic modeling study of 1,3-butadiene combustion: Ignition delay time and laminar flame speed measurements. Combust. Flame 2018, 197, 423-438.

(60) Li, Y.; Zhou, C.-W.; Somers, K. P.; Zhang, K.; Curran, H. J. The oxidation of 2-butene: A high pressure ignition delay, kinetic modeling study and reactivity comparison with isobutene and 1butene. Proc. Combust. Inst. 2017, 36, 403-411.

(61) Bagheri, G.; Ranzi, E.; Pelucchi, M.; Parente, A.; Frassoldati, A.; Faravelli, T. Comprehensive kinetic study of combustion technologies for low environmental impact: MILD and OXY-fuel combustion of methane. Combust. Flame 2020, 212, 142-155.

(62) Smith, G. P.; Golden, D. M.; Frenklach, M.; Moriarty, N. W.; Eiteneer, B.; Goldenberg, M.; Bowman, C. T.; Hanson, R. K.; Song, S.; Gardiner, W. C.; V, V. L., Jr.; Qin, Z. http://www.me.berkeley. edu/gri_mech/.

(63) Baigmohammadi, M.; Patel, V.; Martinez, S.; Panigrahy, S.; Ramalingam, A.; Burke, U.; Somers, K. P.; Heufer, K. A.; Pekalski, A.; Curran, H. J. A Comprehensive Experimental and Simulation Study of Ignition Delay Time Characteristics of Single Fuel C1-C2 Hydrocarbons over a Wide Range of Temperatures, Pressures, Equivalence Ratios, and Dilutions. Energy Fuels 2020, 34, 3755-3771.

(64) Quiceno, R.; Pérez-Ramírez, J.; Warnatz, J.; Deutschmann, O. Modeling the high-temperature catalytic partial oxidation of methane over platinum gauze: Detailed gas-phase and surface chemistries coupled with 3D flow field simulations. Appl. Catal., A 2006, 303, $166-176$.

(65) Wang, H.; You, X.; Joshi, A. V.; Davis, S. G.; Laskin, A.; Egolfopoulos, F.; Law, C. K. USC Mech Version II. High-Temperature Combustion Reaction Model of H2/CO/C1-C4 Compounds. http:// ignis.usc.edu/USC Mech II.htm.

(66) Metcalfe, W. K.; Burke, S. M.; Ahmed, S. S.; Curran, H. J. A Hierarchical and Comparative Kinetic Modeling Study of C1-C2 Hydrocarbon and Oxygenated Fuels. Int. J. Chem. Kinet. 2013, 45, $638-675$.

(67) Burke, S. M.; Burke, U.; Mc Donagh, R.; Mathieu, O.; Osorio, I.; Keesee, C.; Morones, A.; Petersen, E. L.; Wang, W.; DeVerter, T. A.; Oehlschlaeger, M. A.; Rhodes, B.; Hanson, R. K.; Davidson, D. F.; Weber, B. W.; Sung, C.-J.; Santner, J.; Ju, Y.; Haas, F. M.; Dryer, F. L.; Volkov, E. N.; Nilsson, E. J. K.; Konnov, A. A.; Alrefae, M.; Khaled, F.; Farooq, A.; Dirrenberger, P.; Glaude, P.-A.; Battin-Leclerc, F.; Curran, H. J. An experimental and modeling study of propene oxidation. Part 2: Ignition delay time and flame speed measurements. Combust. Flame 2015, 162, 296-314.

(68) Dooley, S.; Burke, M. P.; Chaos, M.; Stein, Y.; Dryer, F. L.; Zhukov, V. P.; Finch, O.; Simmie, J. M.; Curran, H. J. Methyl formate oxidation: Speciation data, laminar burning velocities, ignition delay times, and a validated chemical kinetic model. Int. J. Chem. Kinet. 2010, 42, 527-549.
(69) Karbach, V. Validierung eines detaillierten Reaktionsmechanismus zur Oxidation von Kohlenwasserstoffen bei hohen Temperaturen; Fakultaet Chemie der Ruprecht-Karls-Universitaet Heidelberg: Heidelberg, Germany. 1997.

(70) Baigmohammadi, M.; Patel, V.; Nagaraja, S.; Ramalingam, A.; Martinez, S.; Panigrahy, S.; Mohamed, A. A. E.-S.; Somers, K. P.; Burke, U.; Heufer, K. A.; Pekalski, A.; Curran, H. J. Comprehensive Experimental and Simulation Study of the Ignition Delay Time Characteristics of Binary Blended Methane, Ethane, and Ethylene over a Wide Range of Temperature, Pressure, Equivalence Ratio, and Dilution. Energy Fuels 2020, 34, 8808-8823.

(71) Nagaraja, S. S.; Liang, J.; Dong, S.; Panigrahy, S.; Sahu, A.; Kukkadapu, G.; Wagnon, S. W.; Pitz, W. J.; Curran, H. J. A hierarchical single-pulse shock tube pyrolysis study of C2-C6 1alkenes. Combust. Flame 2020, 219, 456-466.

(72) El-Sabor Mohamed, A. A.; Panigrahy, S.; Sahu, A. B.; Bourque, G.; Curran, H. J. An experimental and kinetic modeling study of the auto-ignition of natural gas blends containing $\mathrm{C} 1-\mathrm{C} 7$ alkanes. Proc. Combust. Inst. 2021, 38, 365-373.

(73) Martinez, S.; Baigmohammadi, M.; Patel, V.; Panigrahy, S.; Sahu, A. B.; Nagaraja, S. S.; Ramalingam, A.; Mohamed, A. A. E.-S.; Somers, K. P.; Heufer, K. A.; Pekalski, A.; Curran, H. J. An experimental and kinetic modeling study of the ignition delay characteristics of binary blends of ethane/propane and ethylene/ propane in multiple shock tubes and rapid compression machines over a wide range of temperature, pressure, equivalence ratio, and dilution. Combust. Flame 2021, 228, 401-414.

(74) Davis, S. G.; Law, C. K.; Wang, H. Propene pyrolysis and oxidation kinetics in a flow reactor and laminar flames. Combust. Flame 1999, 119, 375-399.

(75) Davis, S. G.; Joshi, A. V.; Wang, H.; Egolfopoulos, F. An optimized kinetic model of $\mathrm{H} 2 / \mathrm{CO}$ combustion. Proc. Combust. Inst. 2005, 30, 1283-1292.

(76) Laskin, A.; Wang, H.; Law, C. K. Detailed kinetic modeling of 1,3-butadiene oxidation at high temperatures. Int. J. Chem. Kinet. 2000, 32, 589-614.

(77) Le Cong, T.; Dagaut, P.; Dayma, G. Oxidation of natural gas, natural gas/syngas mixtures, and effect of burnt gas recirculation: Experimental and detailed kinetic modeling. J. Eng. Gas Turbines Power. 2008, 130, No. 041502.

(78) Chen, B.; Togbé, C.; Selim, H.; Dagaut, P.; Sarathy, S. M. Quantities of Interest in Jet Stirred Reactor Oxidation of a HighOctane Gasoline. Energy Fuels 2017, 31, 5543-5553.

(79) Selim, H.; Mohamed, S. Y.; Dawood, A. E.; Sarathy, S. M. Understanding premixed flame chemistry of gasoline fuels by comparing quantities of interest. Proc. Combust. Inst. 2017, 36, $1203-1211$.

(80) Shao, C.; Wang, H.; Atef, N.; Wang, Z.; Chen, B.; Almalki, M.; Zhang, Y.; Cao, C.; Yang, J.; Sarathy, S. M. Polycyclic aromatic hydrocarbons in pyrolysis of gasoline surrogates (n-heptane/isooctane/toluene). Proc. Combust. Inst. 2019, 37, 993-1001.

(81) Chen, B.; Wang, Z.; Wang, J.-Y.; Wang, H.; Togbé, C.; Alonso, P. E. Á.; Almalki, M.; Mehl, M.; Pitz, W. J.; Wagnon, S. W.; Zhang, K.; Kukkadapu, G.; Dagaut, P.; Mani Sarathy, S. Exploring gasoline oxidation chemistry in jet stirred reactors. Fuel 2019, 236, 12821292.

(82) Dagaut, P.; Cathonnet, M.; J P Rouan, R. F.; A Quilgars, J. C. B.; Gaillard, F.; James, H. A jet-stirred reactor for kinetic studies of homogeneous gas-phase reactions at pressures up to ten atmospheres ( $\approx 1 \mathrm{MPa})$. J. Phys. E: Sci. Instrum. 1986, 19, 207.

(83) Dagaut, P.; Karsenty, F.; Dayma, G.; Diévart, P.; Hadj-Ali, K.; Mzé-Ahmed, A.; Braun-Unkhoff, M.; Herzler, J.; Kathrotia, T.; Kick, T.; Naumann, C.; Riedel, U.; Thomas, L. Experimental and detailed kinetic model for the oxidation of a Gas to Liquid (GtL) jet fuel. Combust. Flame 2014, 161, 835-847.

(84) CHEMKIN-PRO 15112, Reaction Design: San Diego; 2012. 